\title{
Glosario de alusiones a vegetales en las obras completas de Cervantes
}

\author{
RAMÓN MORALES*
}

\section{ANTECEDENTES}

Es difícil encontrar algo relacionado con el Quijote de lo que no se haya tratado, ya que existe una extensa bibliografía cervantina. Hasta ahora se conocen los siguientes trabajos sobre este tema específico que aquí se va a desarrollar.

Colmeiro (1895), botánico y director del Jardín Botánico de Madrid durante gran parte de la segunda mitad del siglo XIX, escribe una nota sucinta en donde cita 78 especies vegetales, y aunque el mismo comenta al comienzo que se acercan a un ciento las plantas mencionadas por Cervantes en el Quijote, omite algunas como la achicoria, acíbar, algalia, badea, cantueso, caña, cotufa, ébano, esparraguera, granza, jara, margarita, mirto, palmito, tártago y tuera.

Ceballos (1965), cuando fue nombrado miembro de la Real Academia de la Lengua Española, pronunció un magnífico discurso sobre las plantas en el Quijote. Aunque este autor, ingeniero de montes, ignora el escrito de Colmeiro, ya que dice textualmente que "no conozco trabajos anteriores que se refieran a esta cuestión, ni creo exista alguno que haya tomado el tema como motivo fundamental", recoge la mayoría de las citas, aunque no cita algunas como el acíbar, almendras, arroz, badea, berzas, cañaheja, cáñamo, ébano, esparraguera, grama, granza, lentejas, melón y tuera. Este trabajo has sido reeditado en 1996 con ilustraciones.

* Real Jardín Botánico, CSIC. 
Gómez Tejedor escribió un libro sobre la naturaleza en el Quijote, que fue publicado en 1994, en que cita y comenta 45 especies vegetales que aparecen en el Quijote. Se trata de un libro de bolsillo lleno de erúditos comentarios muy bien documentados. De López García se conoce un librillo titulado Diálogo de encinas en el Quijote, en el que ensalza la encina y todas las referencias a este árbol o a sus frutos en la novela de Cervantes. Al parecer la primera edición es de 1993, y ha sido reeditado en 2005 por ARBA. L. Camacho \& D. Camacho (2001), presentaron en el tercer Congreso internacional de Etnobotánica una contribución sobre los usos del romero en la obra de Cervantes.

Otros escritos que se conocen tratan indirectamente ciertas especies vegetales, como es el caso del trabajo de Valle Nieto (2002), sobre Botica y farmacia en el Quijote, en que se citan algunas plantas medicinales y otras más no medicinales; en total ocho especies, o el de Prieto (2005) sobre el bálsamo de Fierabrás.

Moreno (2005) ha expuesto una conferencia en dos ocasiones, que se sepa, una de ellas en la Universidad Complutense y otra en el Real Jardín Botánico de Madrid. En esta segunda ocasión estaba disponible el texto en fotocopia. En ella trata detalladamente todo lo relacionado con la botánica en la obra Don Quijote de la Mancha. No menciona algunas especies como acíbar, arroz, badea, rubión y las almendras, que las cita como frutos además de como piedra de río y algunos otros aspectos como escarolados, albarrazadas o majagranzas. Al parecer este trabajo se va a publicar próximamente en el Boletín de la Real Sociedad Española de Historia Natural, número 102.

Por fin, Gómez Fernández (2005) ha publicado un artículo en la revista Quercus, cuadernillo especial dedicado a Castilla-La Mancha sobre la Etnobotánica de El Quijote, en que cita 23 especies vegetales, aunque indica que ha localizado hasta 100 especies.

Sin embargo no se conoce ningún trabajo que trate sobre las plantas en las obras completas de Cervantes. Se ha pretendido aquí recopilar todas las citas de Cervantes referentes a plantas y productos vegetales, tanto en el Quijote, como en el resto de sus obras. Ello ayudará sin duda a interpretar a través del mundo vegetal diferentes aspectos de la vida en aquella época.

Hay otros estudios que han recopilado las especies vegetales citadas en grandes obras literarias. Entre los más conocidos son los de las plantas de la Biblia (Moldenke \& Moldenke, 2002), o el trabajo de Ellacombe (1878), que estudió las plantas mencionadas por Shakespeare en toda su obra.

\section{Metodología SEGUIDA}

Se han leído las obras completas de Cervantes, edición Aguilar (1940) y se han anotado todas las referencias a vegetales o productos derivados. Se dispone de un repertorio de 821 citas. Se ha asignado a cada nombre uno científico, teniendo en 
cuenta obras botánicas de la época (Ríos, 1620) y posteriores. Las citas pueden ser alusión directa a la planta, a su uso y en sentido figurado. A continuación se listan en orden alfabético las denominaciones que aparecen en las obras; si son varias se pone como primera la principal. Se asigna a cada una su correspondiente nombre científico y se comentan aspectos botánicos e históricos, aportando en general alguna o varias citas. Si son del Quijote se señala si es la primera o segunda parte en números romanos y el capítulo en arábigos, y la página de la edición de Rico (2004). Para el resto de las obras se indica su nombre y la página de la cita que corresponde a la obra completa del Centro de Estudios Cervantinos de Sevilla \& Rey $(1994,1995)$, indicando entre paréntesis el volumen II o III correspondiente. Solamente para La tía fingida, novela atribuida a Cervantes, se indican las páginas de las Obras completas de 1940 y estas plantas se señalan en la lista con un asterisco.

\section{LISTA DE ESPECIES COMENTADA}

Abrojos: Este nombre se refiere en general a Tribulus terrestris. Son hierbas que viven pegadas al suelo, de hoja dividida y florecillas amarillas y que forman unos frutos bien armados de espinas, capaces de pinchar las ruedas de las bicicletas. Al parecer el nombre vulgar procede de abre ojos, para estar bien atento a no pincharse. En otros tiempos debían herir a caballerías, otros animales y a los mismos viandantes. También se ha denominado a otras especies punzantes con este nombre, como a Centaurea calcitrapa y a $C$. solstitialis. Una cita es: "menester será que el buen Sancho haga alguna disciplina de abrojos" (II, 36: 830).

Acebo: Ilex aquifolium. Arbolillo de hoja perenne, del que se ha encontrado una referencia: "Traía cada uno un grueso bastón de acebo en la mano." (I, 13: 110).

Acíbar: Aloe vera. Es el llamado aloe. Significa con ello lo amargo: "para ella soy miel, y para vosotras acíbar" (II, 44: 886). Se trata de una especie africana, que se difundió por el ámbito mediterráneo probablemente en tiempos de los romanos. Especie de moda en la actualidad en fitoterapia.

Adelfa: Nerium oleander. También se llama baladre. Especie típica mediterránea, que vive natural en las ramblas del sur de la Península y que se cultiva como ornamental por todo el mundo. Es planta venenosa. En las cinco citas conocidas, dos en el Quijote, otras dos en La Galatea y otra más en Los trabajos de Persiles y Sigismunda, se utiliza como corona o para indicar su amargor: "y tan amargo que en su comparación son dulces las tueras y sabrosas las adelfas" (II, 39: 846); "coronada de amarillas y amargas adelfas" (Los trabajos de Persiles y Sigismunda II, 15: 1167(II)). En una ocasión se refiere a que es venenosa: "composición venenosa / con jugo de adelfa amarga" (La Galatea VI: 392(II)). 
Ajos: Allium sativum. Se trata de una planta cultivada muy común en toda España. Su olor impregna a aquellas personas que consumen crudos dientes de ajo, costumbre frecuente en épocas pasadas. El consumo de ajos era propio de personas consideradas de clase baja, según nos da a entender Cervantes por boca de don Quijote, cuando le está aconsejando a Sancho antes de marcharse de gobernador a la ínsula. "No comas ajos ni cebollas, porque no saquen por el olor tu villanería." (II, 43: 872). Al parecer el olor delataba el origen. En otra ocasión dice don Quijote que "me dio un olor de ajos crudos, que me encalabrinó y atosigó el alma" (II, 10: 622), cuando fueron de visita al Toboso, refiriéndose a su señora Dulcinea, sin duda encantada y transformada en rústica labradora que iba montada en su borrico. $\mathrm{O}$ en varias ocasiones cita la expresión despectiva "harto de ajos" como "si soy vieja o no, a Dios daré la cuenta que no a vos, bellaco harto de ajos" (II, 31: 785); "don villano, harto de ajos" (II, 35: 824) o "hija del harto de ajos" (II, 50: 935). Tiene otras muchas especies silvestres este género en el ámbito mediterráneo, lo que puede ser prueba de que es planta oriunda de esta región. Los dientes de ajo crudos son un alimento muy saludable, o si se quiere una medicina de eficacia probada contra el reumatismo y otras dolencias articulares, además de que tiene la facultad de fluidificar la sangre, lo que está muy recomendado para enfermedades cardiovasculares. Además es un antiséptico del tubo digestivo. Cervantes, sin duda influenciado por los prejuicios de la época en la que le tocó vivir, no conoció las facultades saludables de los malolientes ajos.

Álamo: Populus nigra. En cierta ocasión se puede referir a este árbol, aunque en general, como ya se comenta más abajo, el álamo era el nombre vulgar que se daba junto con el de olmo a Ulmus minor. Sin embargo y por su situación junto a sauces en dos citas se ha considerado que puede referirse a Populus nigra. "y que a entrambas bestias las atase muy bien juntas al tronco de un álamo o sauce que allí estaba" (II, 29: 772); o "en el margen sentado de algún río, / de verdes sauces y álamos cubierto" ( $L a$ Galatea IV: 225(II)).

Álamo blanco: Populus alba. Otra especie riparia, que vive pegada a los cauces de los ríos y que gusta del agua a poca profundidad en el suelo. Una de las citas es: "cuando luego se me ofreció a los ojos un cortecido álamo blanco, que delante de mi estaba, en el cual y en otros muchos vi escritas unas letras" (La Galatea I: 90(II)).

Albahaca: Ocimum minimum. Se han encontrado las siguientes referencias de esta planta: "y en el medio un tiesto, que en Sevilla llaman maceta, de albahaca" (Rinconete y Cortadillo: 575(II)); "era abrazarla como quien abraza un tiesto de albahaca o clavellinas" (El rufián viudo, llamado Trampagos: 902(III)). Seguramente se referirá a esta especie, la de hoja estrecha y de menor talla, que se cultiva como ornamental por su fragancia, y porque además ahuyenta moscas y mosquitos. La otra especie

ANALES CERVANTINOS, VOL. XXXVII, PP. 267-295, 2005. ISSN: 0569-9878 
(Ocimum basilicum), de hoja ancha y de la que hay muchas variedades, se utiliza más bien como condimento. Ambas son plantas introducidas en la región mediterránea probablemente en tiempos de Alejandro Magno. De origen asiático, ya se conocían en el sur de España a comienzos de nuestra era, según nos relata Columela en sus célebres libros de Agricultura. Simboliza el buen aroma, como pone de manifiesto la última cita del entremés El rufián viudo, llamado Trampagos.

Albarazados, albarrazadas: Delphinium staphisagria. El nombre vulgar que se da a esta especie es albarraz. Se refiere al color de su flor, entre morado y violeta oscuro, y que tiene un largo espolón. Esta especie arvense es frecuente en barbechos. Se cita en tres ocasiones. "cuáles rubias, cuáles negras, cuáles blancas y cuáles albarrazadas" (II, 39: 847); "dellos son blancos, dellos albarazados, dellos jaspeados y dellos azules" (Retablo de las maravillas: 982(III)); "Oh uvas albarazadas" (El rufián dichoso II: 413(III)).

Alcaparrones: Capparis spinosa. Son los frutos de la alcaparra, que se suelen preparar en encurtido. Esta especie vive en las regiones áridas del sur de España. Citada en Rinconete y Cortadillo (578(II)): "con su llamativo de alcaparrones ahogados en pimientos".

Alcornoque, corcho, corchos: Quercus suber. Especie citada a lo largo de toda la obra profusamente, en total 18 veces; la mayoría de ellas como árboles que se encuentran en las correrías del caballero andante y su escudero, en algunas ocasiones en sentido figurado: "aunque la halle más dura que un alcornoque" (I, 25: 241), o "corazón de alcornoque" (II, 35: 825). Se trata de un árbol que en general es más corpulento que la encina, con hojas también perennes, pero mayores y más lustrosas, y sin pelos por la parte de abajo o envés. Gusta de vivir en lugares de suelos más profundos y de características ácidas, por lo que es más frecuente en la mitad oeste peninsular. Como se sabe su corteza se engrosa, porque se produce una gran cantidad de una sustancia elástica denominada suberina, que vulgarmente se llama corcho, producto de amplia utilización popular en España y Portugal, para elaborar y forrar objetos de uso doméstico, y con múltiples usos industriales como aislante acústico y térmico, para la fabricación de objetos, en zapatería o para forrar paredes o suelos. Como tapones de botella el corcho es un material insustituible. La palabra corcho no se ha encontrado citada en el Quijote, pero sí en Rinconete y Cortadillo: "y un corcho que podría caber sosegadamente y sin apremio hasta un azumbre" (585(II)); " lo trasegó del corcho al estómago" (586(II)); "y a la guía tocó el escanciar con el corcho de colmena" (587(II)). Se refiere a un recipiente. En Los trabajos de Persiles y Sigismunda (II, 18: 1183(II)) cita "vasos de corcho, con maestría labrados". En una ocasión se refiere a las agallas que se producen en el alcornoque: "haber mudado las perlas de los ojos de mi señora en agallas alcornoqueñas" (II, 10: 622).

Alfalfa: Medicago sativa. Otros nombres populares de esta planta es alfalce o mielga, y se trata de plantas muy apetecidas por el ganado. Una única 
cita se refiere a un nombre propio en Rinconete y Cortadillo (598(II)): "Al bodegonero de la Alfalfa".

Algalia: Abelmoschus moschatus. Especie cuyas semillas son utilizadas en perfumería por su aroma característico. Se cita en tres ocasiones: "sino ámbar y algalia entre algodones" (I, 4: 54); "al soldado mejor le está el oler a pólvora que a algalia" (II, 24: 740); "y que su aliento era de puro ámbar, almizcle y algalia" (Licenciado Vidriera: 663(II)).

Algarroba, algarrobos: Ceratonia siliqua. Las algarrobas son el fruto del algarrobo, árbol cultivado profusamente en tiempos pasados y asilvestrado en parte de la Península Ibérica. Se cita en cuatro ocasiones; una de ellas es: "a quien hacen compañía cuatro docenas de algarrobas" (II, 13: 642). El nombre genérico de esta especie, Ceratonia, y quilate tienen la misma etimología, ya que sus semillas, de peso siempre constante, se han utilizado como medida de joyeros desde la antigüedad.

Algodón: Gossypium herbaceum. Se cita únicamente como cosa blanda y suave: "algalia entre algodones" (I, 4: 54); "con dárselas en el agua, o en alguna cosa blanda, como algodón" (I, 25: 240); "qué martas cebollinas o qué copos de algodón cardado pone en las talegas, para no quedar molidos los cascos y hechos alheña los huesos" (II, 14: 649); "que las lágrimas de una afligida hermosura vuelven en algodón los riscos" (II, 35: 826); "y halagarme para que yo me hiciese de lana y de algodón cardado" (II, 35: 827); "aunque soy rústico, mis carnes tienen más de algodón que de esparto" (II, 36: 830).

Alhelí: Erysimum cheiri. Esta especie de flores amarillas es rústica y se encuentra con frecuencia asilvestrada en los alrededores de pueblos y viviendas. Los alhelíes morados corresponden sin embargo a otra especie perteneciente a la misma familia botánica de las crucíferas, Matthiola incana. Se cita en tres ocasiones, dos de ellas en sentido figurado: "y me entretuve con las cabrillas, que son como unos alhelíes y como unas flores" (II, 41: 863); o "alhelí y alfaquí, tanto por el al primero como el $i$ en que acaban, son conocidos por arábigos" (II, 67: 1062).

Alheña: Ligustrum vulgare. El aligustre es especie natural en la Península Ibérica, que forma parte de nuestros matorrales en lugares algo húmedos, más frecuente en la mitad norte. También se cultiva frecuentemente como ornamental para formar setos. En varias ocasiones se menciona la alheña, tinte utilizado desde antiguo. Para obtener dicho tinte había que machacar bien la planta: "envió al loco hecho una alheña" (II, Prólogo: 545); "y dejan a sus buenos escuderos molidos como alheña o como cibera en poder de los enemigos" (II, 28: 767). También se denomina así a la especie Lawsonia inermis y al tinte que se obtiene de ella en el norte de África.

Alholvas: Trigonella foenum-graecum. Hierba recomendada para personas delgadas e inapetentes, porque al parecer abre el apetito. Contiene hormonas vegetales, la llamada diosgenina, por lo que se toma en el norte de África 
para estimular la secrección de leche en madres lactantes, y como "alentador de una fascinante redondez del seno". Se cita en la expresión "y yo quiero que sea no más de un real, que no puede ser menos, aunque coma alholvas" (Coloquio de Cipión y Berganza: 959(II)).

Alhucema: Lavandula latifolia. El espliego es muy común en la mitad este la de Península Ibérica sobre sustratos calizos. Se cultiva como ornamental en jardinería y para la obtención de aceites esenciales, que se usan en cosmética e industria farmacéutica y alimentaria. Es citado una vez: "Y este nombre albogues es morisco, como lo son todos aquellos que en nuestra lengua castellana comienzan en al, conviene a saber: ..., alhucema" (II, 67: 1062).

Aliagas: Genista scorpius. La aliaga o aulaga es un matorral armado de espinas. Dicha especie se encuentra extendida por todos los sustratos calizos del este de España. Solamente se menciona a la entrada de Barcelona, cuando la travesura de los muchachos que alzaron las colas de Rocinante y el rucio y "les pusieron y encajaron sendos manojos de aliagas" (II, 61: 1020), con lo que dieron con sus dueños en tierra.

Almendro, almendras: Prunus dulcis. Los almendros (Prunus dulcis) son árboles de hoja caduca, muy rústicos y bien adaptados a nuestro clima, aunque oriundos del este de la región mediterránea. Fueron introducidos probablemente a través de las primeras colonias que establecieron los griegos en las regiones litorales de España. Su floración es espectacular, porque los árboles, aún sin hojas, se cuajan de flores que llenan los alrededores de un olor amielado. Los abejas aprovechan sus primeras salidas invernales para libar el néctar de tan dulces flores. El período de floración varía dependiendo de la latitud, la altitud y el año meteorológico, pero por el centro de España suele ocurrir entre mediados de febrero y mediados de marzo. Cervantes debió ver muchas veces en sus viajes los almendros en flor y oler su fragancia. Y sin embargo, no nos deja de extrañar que no cite dicho árbol más que en una ocasión en su obra de teatro Pedro de Urdemalas (I: 808(III)): “ ¿Qué almendro, guindo o manzano / has visto tu que se viese / en dar su fruto temprano". La almendra era además fruto seco común que se debía consumir bien crudo o elaborado en dulce. No hay que olvidar la leche de almendras, ni que esta picada se utiliza como parte de muchos platos cocinados. Solamente se conocen dos referencias a esta planta en el Quijote, una de ellas: "aunque eran blancos como unas peladas almendras" (II, 23: 728), cuando se refiere a los dientes de la señora Belerma, que don Quijote aseguró ver en la cueva de Montesinos. Otra de ellas es: "merced a las muchas pasas y almendras que había comido" (El casamiento engañoso: 890(II)).

Amapola: Papaver rhoeas. Especie introducida probablemente como planta acompañante de semillas de cereales, pero hace unos cuantos miles de años, por lo que se considera ya especie propia de nuestros campos. Se 
cita como comparación de color encarnado: "poner las posaderas como unas amapolas" (La ilustre fregona: 778(II)).

Amaranto: Amaranthus caudatus. Es de las especies cultivadas de este género, probablemente, la más vistosa de todas. Una cita es: "traían guirnaldas de jazmines, rosas, amaranto y madreselva compuestas" (II, 20: 702).

Anís: Pimpinella anisum. La única cita de esta especia es en La entretenida (I: 699(III)): "anís y cochinilla, fue sin número".

Arroz: Oryza sativa. El arroz se cultiva en las regiones costeras mediterráneas de España desde hace al menos mil años. La siguiente referencia, la única: "hay tanto que trasquilar en las dueñas, según mi barbero, cuanto será mejor no menear el arroz, aunque se pegue" (II, 37: 837), pone de manifiesto que debía ser ya comida relativamente usual, si había entrado en el saber popular a través de los refranes.

Avellana, avellanada: Corylus avellana. Arbolillo silvestre muy ramificado que aparece en lugares umbríos y húmedos y que se ha manejado y se cultiva también por su madera, sobre todo para utilización en cestería, además de la recolección de su fruto. Se cita su fruto en diez ocasiones. Además se utiliza refiriéndose a enjuto: "pero fuerte, tiesa, nervuda y avellanada (II, 50: 930).

Azafrán: Crocus sativus. Especie cultivada en España desde antiguo, que se usa como aderezo y para dar color a la comida, además de ser planta tinctorea, según se manifiesta en El cerco de Numancia (II: 1154 (III)): "la otra teñida con azafrán".

Azúcar: Saccharum officinarum. La caña de azúcar es una especie oriunda del subcontinente indio que fue traída a España en la Edad Media por los árabes y cultivado en el litoral mediterráneo. Se conoce una cita de este producto vegetal: "Alcuzcuz como sabroso, / sorbeta de azúcar bebo" (Trato de Argel III: 1089(III)).

Azucena: Lilium candidum. Especie oriunda de la región este del Mediterráneo, se cultiva desde hace más de tres mil años. Se conoce una reproducción de esta planta de época micénica de la isla de Creta. Simboliza la pureza por su blancura. Recibe muchos nombres vulgares, pero uno de ellos nos da indicio de su época de floración aproximada en el centro de España, aunque ello varía con el año meteorológico: varas de San Antonio; santo que se celebra el 13 de junio. El aroma de las azucenas es delicadísimo, pero penetrante, por lo que se dice que dentro de una habitación cerrada puede llegar a marear. Una de las tres citas es: "en una mejilla tiene el sol y en la otra la luna; la una es hecha de rosas y la otra de claveles y en entrambas hay también azucenas y jazmines" (La ilustre fregona: 752(II)), que es parte de la descripción de Constanza, la ilustre fregona.

Badeas: Citrullus lanatus. Con el nombre de badea se refiere el autor a la sandía, aunque también se ha empleado este nombre vulgar para melones de baja calidad y para pepinos. Se encuentra la siguiente cita: "que así 
acomete mi señor a cien hombres armados como un muchacho goloso a media docena de badeas" (II, 4: 578).

Beleño: Hyoscyamus albus El beleño más frecuente en la mitad sur de España es Hyoscyamus albus, aunque $H$. niger se ha utilizado de forma similar. Varias citas ponen de manifiesto las propiedades narcóticas de esta planta, cuando se cita en La Galatea (V: 318(II)) que "Tu has quitado la fuerza al beleño / con que el amor ingrato / adormecía a mi virtud doliente,". Se conoce otra cita del Viaje al Parnaso (VIII: 1338(III)): "Morfeo, el dios del sueño, por encanto / allí se apareció, cuya corona / era de ramos de beleño santo."

Berenjena, berenjeneros, aberenjenado: Solanum melongena. Hortaliza citada en varias ocasiones, en una de ellas aludiendo al color: "de color amoratado, como de berenjena" (II, 14: 650). Otras: "que el autor de la historia se llama Cide Amete Berenjena (II, 2: 565); "he oido decir que los moros son amigos de berenjenas" (II, 2: 565); "ni los cazoleros, berenjeneros, ballenatos, jaboneros, ni los de otros nombres" (II, 27: 764); "porque son jaspeados de azul y verde y aberenjenado" (II, 47: 906).

Berros: Rorippa nasturtium-aquaticum. Planta acuática, que es verdura silvestre muy apreciada, y se debe recolectar antes de que florezca. En el Coloquio de Cipión y Berganza (937(II)) nos relata Cervantes que una mujer supuestamente bruja hacía "nacer berros en una artesa", lo que pone como prueba de sus poderes.

Berzas, coles, Repollo: Brassica oleracea. Dos citas en sentido figurado y una como nombre propio: "yo apostaré, -replicó Sancho- que ha mezclado el hideperro berzas con capachos" (II, 3: 571); "de tronchos de coles sé / que hiciera invenciones mil" (Pedro de Urdemalas II: 819(III)); "Benito Repollo" (Retablo de las maravillas: 975(III)).

Biznaga: Ammi visnaga. Los radios de la inflorescencia de esta planta se utilizaban como palillos de dientes. Esta especie se cita en La guarda cuidadosa (942(III)) en dos ocasiones.

Bledos: Amaranthus blitum. Debía ser planta frecuente que se comía como verdura cocinada y que ha caído en desuso en la actualidad. Citada en el dicho de "Regostose la vieja a los bledos" (II, 69: 1072).

Boj: Buxus sempervirens. Esta especie se utilizaba de siempre para hacer pequeños utensilios o cubiertos, tenedores y cucharas, por lo que se mantenía cultivada en los claustros de los monasterios. Son notables por su tamaño los del claustro de la catedral de Segovia. Su madera es, como ya indica Cervantes, de color amarillento. En La Galatea (III: 172(II)) cita que un pastor llega con "un cayado de amarillo boj en la mano".

Cacao: Theobroma cacao. Aunque ya se conocía en España por entonces este producto, traído de Nueva España o Méjico, no debía ser de uso habitual todavía y al parecer se valoraba poco aún. En La gitanilla (482 (II)) se dice que: "no lo estimamos en un cacao".

Calabaza: Lagenaria siceraria. La calabaza se refiere sin duda a la calabaza vinatera del Viejo Mundo, utilizada como recipiente o partida en dos, 
como escudilla. Como es sabido, las tres especies más frecuentemente cultivadas en la actualidad son Cucurbita maxima, C. pepo y C. ficifolia, originarias de América. Es citada cuando dice: "aquí llevo una calabaza llena de lo caro" (II, 66: 1058); o "desenvainó su calabaza" (II, 66: 1059).

Cambroneras: Lycium barbarum. Es la especie de cambronera más frecuente, aunque también se ha utilizado como seto espinoso en lugares áridos $L$. europaeum. El nombre de cambrón se utiliza para otros matorrales con espinas del género Genista o Adenocarpus. Una de las tres citas es la de la entrada a la cueva de Montesinos "cuya boca es espaciosa y ancha, pero llena de cambroneras" (II, 22: 719).

Cantueso: Lavandula pedunculata. Se menciona esta planta dos veces en sentido figurado: "y aun todo esto fueran flores de cantueso, si no tuviéramos que entender con yangüeses y con moros encantados" (II, 5: 582); "pero todas esas son flores de cantueso viejas" (Rinconete y Cortadillo: 580 (II)).

Caña, cañaveral: Arundo donax. Una de las plantas que más veces se cita, en 35 ocasiones, 24 de ellas en el Quijote, y en muchas de sus obras. Según describe Cervantes, con ella se hacen multitud de utensilios, como un canuto, un silbato: "sonó su silbato de cañas cuatro o cinco veces" (I, 2: 40), una caña de pescar, una cruz: "una pequeña cruz hecha de cañas" (I, 40: 312).

Cañaheja: Ferula communis. Esta especie pertenece a la familia de las umbelíferas, y es planta relativamente frecuente que crece hasta dos metros en un año y cuando se seca da una caña bastante resistente y ligera, utilizada como bastón o vara, que era usada por los antiguos maestros para enderezar a alumnos descarriados. No sabemos si viene de ahí la expresión de "estar bajo la férula". A veces también se ha denominado a la cicuta, Conium maculatum, con este nombre. Se cita en el juicio de Sancho, el gobernador de la ínsula, sobre el préstamo de las monedas: "el uno traía una cañaheja por báculo" (II, 45: 890); "Pues ¿vale esta cañaheja diez escudos de oro?" (II, 45: 891); "se rompiese y abriese la caña" (II, 45: 891), refiriéndose a la cañaheja; "que en aquella cañaheja estaban aquellos diez escudos" (II, 45: 892).

Cáñamo: Cannabis sativa. Se trata de una planta de suma utilidad, para obtención de fibra y de cañamones. Se conocen dos citas: "todos vestidos de yedra y de cáñamo teñido de verde" (II, 20: 702); "gruesa cuerda de cáñamo" (Los trabajos de Persiles y Sigismunda I, 1: 985(II)).

Carda: Dipsacus sativus. Hay una cita que no parece referirse a esta planta en el Viaje al Parnaso: "entre los de la carda".

Castaño: Castanea sativa. En I, 20: 183 cita este árbol: "y vio don Quijote que estaba entre unos árboles altos, que ellos eran castaños, que hacen la sombra muy escura"; o "y habiendo andado una buena pieza por entre aquellos castaños y árboles sombríos, dieron en un pradecillo". En el Prólogo de las Novelas ejemplares (430(II)) esboza Cervantes su 
autorretrato, y describe su "cabello castaño". En otra ocasión se refiere a que el "color salía de castaño" (La ilustre fregona: 759(II)).

Cebada, alcacel: Hordeum vulgare. Se cita la cebada para las cabalgaduras, a veces la cebada y la paja. En otra ocasión se menciona el alcacel o cebada verde segada, que se daba como forraje al ganado, aunque la cita es en sentido figurado: "Pues en verdad que está ya duro el alcacel para zampoñas." (II, 73: 1098). Sin embargo no se encuentra en sus obras completas alusión alguna a la cerveza. Es probable que ni se elaborara ni se consumiera en España en aquella época.

Cebolla, cebolluda: Allium cepa. Era habitual tomarla cruda, según pone de manifiesto Sancho: "Aquí trayo una cebolla y un poco de queso" (I, 10: 94); "aunque sea pan y cebolla" (I, 11: 96); "y así me sustentaré Sancho a secas con pan y cebolla como gobernador con perdices y capones" (II, 43: 876); "aunque fuese un pedazo de pan y una cebolla" (II, 47: 905); "el cual está acostumbrado a cabra, a vaca, a tocino, a cecina, a nabos y a cebollas" (II, 49: 918). Es mencionada además en dos ocasiones como parte de ciertos guisos: "donde le dieron de cenar un salpicón de vaca con cebolla" (II, 49: 918), cuando por fin dejaron comer a Sancho siendo gobernador de la ínsula; o "están cocidas con sus garbanzos, cebollas y tocino"(II, 59: 999), plato que les ofrece el ventero de la venta cuando el viaje a Barcelona. No falta tampoco el simbólico adjetivo "ora estés, señora mía, transformada en cebolluda labradora" (II, 48: 909). Su olor característico es debido a unos compuestos azufrados muy volátiles, irritantes, que estimulan la secreción de las mucosas y que por eso hacen llorar al cortarlas. Pero también les hace eficacísimos contra la tos. Hasta algunos médicos recetan en la actualidad poner una cebolla cortada por la mitad y abierta en la habitación de una persona con tos insistente y seca. Su olor impregna a las personas que la consumen habitualmente cruda, aunque no da tanto olor al aliento, como ocurre con el ajo. Cocinada pierde su olor desagradable, al descomponerse los compuestos azufrados con la cocción.

*Cebolla albarrana: Urginea maritima. Especie venenosa que se cita en una ocasión en sentido figurado: "la mirra no es de algún provecho, ni la cebolla albarrana" (La tía fingida: 1307).

Cedacillo: Briza media. Hierba perteneciente a la familia de las gramíneas, que se menciona en dos ocasiones: "la que echa por cinco blancas / las habas y el cedacillo" (El rufián dichoso I: 382(III)); "que va a las embusteras / del cedacillo y habas" (La entretenida III: 734(III)).

Cedro: Cedrus atlantica. Es el que se cultiva en España con más frecuencia, y es oriundo de Marruecos, en donde forma bosques naturales Las otras dos especies, el del Himalaya y el del Líbano, también se cultivan en nuestro país. Como es sabido, la madera del cedro del Líbano era muy apreciada en todo el ámbito mediterráneo. Se conocen las siguientes citas: "ni menos a la tierra trae rendidos / los altos cedros Bóreas, cuando, airado, / quiere humillar los más fortalecidos:" (Viaje al Parnaso II: 
1246(III)); o "por entre palmas / y entre cedros altos / y entre árboles pacíficos de oliva;" (Viaje al Parnaso III: 1274(III)).

Cerezas: Prunus avium. Se cita una única vez este fruto en La Galatea (III: 200(II)) "Todo el bien suceda en colmo / entre desposados tales, / tan para en uno nascidos; / peras les ofrezca el olmo, / cerezas los carrascales, / guindas los mirtos floridos, / hallen perlas en los riscos, / uvas les den los lentiscos, / manzanas los algarrobos".

Chicoria: Cichorium intybus. El agua de achicoria se preparaba cociendo la raíz o toda la planta. La tisana amarga tiene propiedades digestivas. La única cita es: "que, como tenía el estómago lleno, y no de agua de chicoria" (I, 8: 78).

Cinamomo: Melia azedarach. Este árbol ornamental, traído de Oriente se cita únicamente en Los trabajos de Persiles y Sigismunda (III, 5: 1230(II)): "El cinamomo, el plátano y la rosa / de Hierico se halla en sus jardines".

Ciprés: Cupressus sempervirens. Árbol oriundo del este de la región mediterrránea, se encuentra de manera natural en Chipre, de donde proviene su nombre. Mencionado en 16 ocasiones y solamente 3 de ellas en el Quijote, para hacer coronas o guirnaldas. y a veces con la connotación de funesto, por la costumbre de plantarlo en los cementerios. Una cita es: "y coronadas las cabezas con guirnaldas de ciprés" (I, 13: 110)

Cizaña: Lolium temulentum. Se cita como mala hierba y en sentido figurado, ya que representan la maldad extendida por el mundo. En Los trabajos de Persiles y Sigismunda (I, 16: 1057(II)): "¿Por qué ha de esperar el que siembra cizaña y maldad, dé buen fruto su cosecha?" O en el Trato de Argel (II: 1070(III)) "sembró la cruda y la mortal cizaña / del robo, de la fraude y del engaño, / del cambio injusto y trato con maraña".

Clavel: Dianthus caryophyllus. Planta ornamental que se cita dos veces en sentido figurado: "en una mejilla tiene el sol y en la otra la luna; la una es hecha de rosas y la otra de claveles y en entrambas hay también azucenas y jazmines" (La ilustre fregona: 752(II)); "Viene / y a donde pone la hermosa planta / un clavel o azucena se levanta" (La gran sultana Doña Catalina de Oviedo III: 539(III)).

Clavelina, clavellinas: Dianthus plumarius. Esta flor ornamental es citada en dos ocasiones: "acullá la olorosa clavelina" (La Galatea I: 66(II)); "era abrazarla como quien abraza un tiesto de albahacas o clavellinas" ( $E l$ rufián viudo, llamado Trampagos: 902(III)).

Cocos: Cocos nucifera. Varias citas que se refieren a persona que asusta o es fea y no a la planta.

Cotufas: Cyperus esculentus. Las chufas se citan en el dicho "pedir cotufas en el golfo" (I, 30: 306; II, 3: 569; II, 20: 698) en tres ocasiones.

Ébano: Diospyrus ebenum. Árbol oriundo de las selvas del sudeste asiático, del que se obtiene madera noble. Su duramen es negro. Hay referencias a una cajita, a una cruz y a un bastón: "arrimada a un báculo de negro y finísimo ébano" (II, 70: 1078). 
Embelesamiento, embelese: Plumbago europaea. La belesa se utiliza para pescar peces en los remansos de los ríos, atontándolos. Una cita es: "esperando en qué había de parar aquel embelesamiento" (I, 23: 220).

Encina, encinal, encinar, carrascales, bellotas: Quercus ilex. Árbol o arbusto que recibe también los nombres de chaparra, mataparda o sardón. Dichos nombres han dado lugar a numerosos fitotopónimos en toda España. El encinar de El Pardo se denomina así por su color característico, verde grisáceo amarronado, o sea, pardo. El encinar es el bosque más extenso en la mayor parte de España, por lo que la encina debiera ser el árbol nacional español. Es el que más se cita en la obra, junto con sus frutos, las bellotas. Se han encontrado en total 52 referencias a esta especie. En una ocasión se refiere Cervantes a "don Quijote, dormitando al [pie] de una robusta encina" (II, 12: 634). Tambien se cita la formación de encinas: "se emboscó en la floresta, encinar o selva junto al gran Toboso" (II, 10: 614), y dos veces más en La Galatea, en una de ellas como encinal. Otras muchas veces sirven estos árboles tan frecuentes para atar a Rocinante o al Rucio, o es donde se encuentra atado al criado al que azota su amo. Cuando Cervantes menciona las dehesas, se refiere probablemente a la formación de encinar adehesado tan frecuente en muchas regiones españolas: "dehesas del tortuoso Guadiana" (I, 18: 160). En una ocasión se refiere a esta planta en sentido figurado: "con un corazón de encina (II, 70: 1082), dada la dureza de su madera. Por eso los pastores fabrican con el corazón de encina los badajos de los cencerros, que duran mucho sin desgastarse. En varias ocasiones alude a la "robusta" o "antigua encina" por lo corpulentos y viejos que pueden llegar a ser estos árboles; como símbolo de vigor y longevidad. La alusión a encinas y encinares es una constante en toda la literatura española. Además las bellotas han sido una fuente de fécula, sustituida por el cereal, la castaña y la patata sucesivamente, aunque se siga consumiendo en caso de necesidad. Una cita es la que se refiere a "gran cantidad de bellotas avellanadas" (I, 11: 97).

Enea, espadañas: Typha domingensis. También se llaman así a otras especies menos frecuentes, Typha latifolia y $T$. angustifolia. Son plantas que viven en las orillas de zonas encharcadas o riachuelos. Sus hojas retorcidas se utilizaban y se siguen utilizando para tejer "estera de enea" (I, 16: 141; I, 17: 150), o asientos de silla.

Enebro, miera: Juniperus oxycedrus. En Rinconete y Cortadillo (559(II)) se refiere a los "untos de miera", especie de brea obtenida de la madera del enebro de la miera, y utilizados para enfermedades de la piel. En $L a$ Galatea también cita este árbol.

Escarolados: Cychorium endivia. Citada como modelo de forma rizada o escarolada: “ ¿Por qué sus cuellos por la mayor parte han de ser siempre escarolados, y no abiertos con molde? (II, 44: 882).

Espárrago, esparraguera: Asparagus officinalis. Dos citas se refieren a esta planta comestible: "que trae por empresa en el escudo una esparraguera" 
(I, 17: 159); "hecha arista el alma, seca y sola como espárrago!" (El rufián dichoso II: 439(III)).

Esparto: Stipa tenacissima. El esparto o atocha vive en el oeste de la región mediterránea. Muy abundante en España, es utilizado para obtención de fibra desde tiempos prehistóricos, como demuestra el ajuar de objetos elaborados con esparto encontrado en la cueva de los Murciélagos, Albuñol (Granada), de 5.500 años de antigüedad. Fue fibra importante hasta mediados del siglo pasado. Simboliza lo basto, áspero y seco: "leyenda seca como un esparto" (I, Prólogo: 8); "porque ya estaban más enjutas y secas que un esparto" (II, 54: 962); "pues las has habido con una alma de esparto y con un corazón de encina" (II, 70: 1082).

Fresno: Fraxinus angustifolia. Especie que vive en la mitad sur de España. Dos de las tres citas son: "vieron sentado al pie de un fresno" (I, 28: 275); "me senté al pie de un alto fresno" (La Galatea I: 55(II)).

Garbanzos: Cicer arietinum. Mencionado solamente en el Quijote tres veces. Una de ellas es: "que a venir frisada descubriera cada grano del grandor de un garbanzo de los buenos de Martos" (II, 38: 838).

Ginjo: Ziziphus jujuba. El azufaifo es un arbolillo que se cultiva sobre todo en el sur de España. En portugués se nombra a las guindas (Prunus cerasus) con este nombre. Las dos citas conocidas son: "siempre quedaba como un ginjo verde" (El rufián viudo, llamado Trampagos: 901(III)); "El mozo es como un ginjo verde" (El viejo celoso: 1004(III)).

Grama: Cynodon dactylon. Hierba citada cuando Sancho descompone la palabra gramática, diciendo que:"con la grama bien me avendría yo" (II, 3: 571).

Granado, granada: Punica granatum. Arbolillo silvestre y cultivado, del que se conoce una variedad enana, con las granaditas también proporcionalmente pequeñas. Los frutos de la planta silvestre son muy agrios. Se conocen las siguientes menciones: "por lo menos se dividirían y fenderían de arriba abajo y abrirían como una granada" (I, 9: 84), en la batalla de don Quijote con el vizcaino; o lo que dice Sancho "que le abrieran de arriba abajo como una granada" (II, 32: 796), si Amadis de Gaula oyera las razones del cura en casa de los duques; o que Sancho "en el tiempo que fue gobernador aprendió a comer a lo melindroso: tanto, que comía con tenedor las uvas, y aún los granos de la granada" (II, 62. 1022). Otra cita del Coloquio de Cipión y Berganza (952(II)) es: "amanecía sentado al pie de un granado, de muchos que en la huerta había".

Gualdas: Reseda luteola. Planta colorante que tiñe de tonalidades amarillentas. Se conoce la cita: "Haga el suelo de esmeraldas / la juncia, y la flor de gualdas" (Pedro de Urdemalas II: 811(III)).

Guindo, guindas: Prunus cerasus. Árbol próximo al cerezo, pero de frutos más pequeños y agrios. Se han encontrado siete citas, algunas en sentido figurado: "como quien dice: bebe con guindas" (II, 35: 827); "No me importa a mí una guinda / pronunciar con dinguindujes" (La entretenida 
III: 757(III)); o "cogiendo guindas la mañana de San Juan" (Los trabajos de Persiles y Sigismunda III, 21: 1319(II)).

Habas: Vicia faba. Se menciona esta planta de huerta en seis ocasiones, sobre todo en dichos. Algunas citas son: "en otras casas cuecen habas, y en la mía, a calderadas" (II, 13: 641); "como si fueran hechos de habas, como los frailecicos que hacen los niños" (I, 32: 323); "que oficio que no da de comer a su dueño no vale dos habas" (II, 47: 902).

Hayas: Fagus sylvatica. Cuando menciona el haya, probablemente se refiera al aliso (Alnus glutinosa). En la actualidad no hay hayas en la Mancha ni las había en aquellos tiempos. Las citas referentes al haya pueden ser figuradas. O que Cervantes tuviera simpatía o apego a este árbol, del que sin duda se utilizaba su madera noble en ebanistería, aunque fuera traída del norte de España. Además, el haya es el paradigma de árbol que da una sombra impenetrable. García Río \& al. (2002) indican que en algunos lugares manchegos aún hoy día se nombra al arce de Montpellier (Acer monspessulanum) con un nombre vulgar parecido al de haya. Ello podría dar indicio de que se refiere a esta especie, aunque las hojas de este arbolillo tienen un aspecto muy diferente de las del haya, ya que son palmeadas. "Haie" en francés significa seto y era frecuente y lo sigue siendo la confección de setos en los jardines centroeuropeos con carpe (Carpinus betulus) y haya. Es posible, por lo tanto, que hace cuatro siglos se tratara de un nombre genérico para especies que tienen sus hojas con nerviación paralela bien marcada, como la del haya, carpe o aliso. Lo más razonable es que se refiera al aliso, ya que como haya denominan a Alnus glutinosa en ciertas traducciones de escritos andalusíes (Carabaza \& al., 2004). Estos árboles sí se encuentran con relativa frecuencia por los lugares del Quijote, junto a los cursos de agua. Son siete las referencias a hayas en el Quijote, constantes a lo largo de toda la novela, y una más en La Galatea: "No está muy lejos de aquí un sitio donde hay casi dos docenas de altas hayas, y no hay ninguna que en su lisa corteza no tenga grabado y escrito el nombre de Marcela (I, 12: 108); "Con esto se metieron en la alameda, y don Quijote se acomodó al pie de un olmo y Sancho al pie de una haya, que estos tales árboles y otros semejantes siempre tienen pies, y no manos" (II, 28: 771); "se sentaron al pie de una haya" (II, 54: 962); "se retiró hasta veinte pasos de su amo, entre unas hayas" (II, 71: 1085); "y dando un desaforado azote en una haya" (II, 71: 1086); "a costa de las cortezas de las hayas" (II, 72: 1093); "y los versos que el otro día en las hayas de aquel bosque escribiste" ( $L a$ Galatea: II: 138 (II)). Quizá la clave sea esta cita: "arrimado a un tronco de una haya o de un alcornoque que Cide Hamete Benengeli no distingue el árbol que era" (II, 68: 1067).

Hiedra, yedra: Hedera helix. Planta trepadora silvestre y cultivada. Se cita profusamente y en 14 ocasiones, en sentido figurado y en alusión directa: "sino de algunas hojas verdes de lampazos y yedra entretejidas (I, 11: 98); "todos vestidos de yedra y de cáñamo teñido de verde" (II, 20: 702); 
"cuando a deshora entraron por el jardín cuatro salvajes, vestidos todos de verde yedra, que sobre sus hombros traían un gran caballo de madera" (II, 41: 854); o "dejadme llegar al muro de quien yo soy yedra" (I, 36: 377).

Higos, higas, breva, cabrahigo, higueral: Ficus carica. Árbol de suma importancia por sus frutos, que se consumen maduros o secos. Se citan en 10 ocasiones. Son algunas de ellas: "hacia la parte de Orán, en el cual hay mucha contratación de higos pasos" (I, 41: 419); "llegaron a la cueva, cuya boca es espaciosa y ancha; pero llena de cambroneras y cabrahígos, de zarzas y malezas" (II, 22: 719), que se refiere a la cueva de Montesinos. O en sentido figurado: "no se me da un higo que digan de mí todo lo que quisieren" (II, 8: 604); "no se me da por cuantas dueñas hay un cabrahígo" (II, 37: 837); "que si no os ablandáis más que una breva madura" (II, 35: 827); "santígüense, y den al diablo / dos higas de su higueral" (La ilustre fregona: 772 (II)).

Hinojos, finojos: Foeniculum vulgare. Se refiere siempre a caer de hinojos o de rodillas, aunque también sea el nombre vulgar de esta especie.

Incienso: Boswellia sacra. Resina de una especie arbórea oriunda de Etiopía. Se cita en cinco ocasiones, cuatro de ellas en El cerco de Numancia y otra en La Galatea (IV: 335 (II)): "comenzó a rodear la pira y a echar en todos los ardientes fuegos alguna cantidad de sacro y oloroso incienso".

Jarales: Cistus ladanifer. Formaciones de matorral frecuentes y extendidas en España. Hay dos menciones; una de ellas es: "y se emboscó corriendo por entre estos jarales" (I, 23: 220). Se cita también jara en varias ocasiones, refiriéndose a venablo.

Jazmín: Jasminum officinalis. Enredadera que se cita en siete ocasiones, sobre todo como ornamental y para la confección de guirnaldas: "traían guirnaldas de jazmines" (II, 20: 702).

Jeringa: Philadelphus coronarius. En II, 51: 945 dice: "si no es algunos cañutos de jeringas".

Juncia: Cyperus longus. Hierba perenne de rizoma aromático. Algunas citas son: "a cortar ramos y a coger juncia y flores y verdes espadañas para adornar el templo y calles de nuestro lugar, por ser el siguiente día solemnísima fiesta" (La Galatea I: 67(II)); "cubierto de verde juncia, y oloroso con diversas flores" (Los trabajos de Persiles y Sigismunda II, 10: 1136(II)); "y adornáronle de ramos y juncia" (La gitanilla: 477(II)).

*Junco de las Indias: Calamus rotang. Se trata de una palmera trepadora oriunda de las selvas del sudeste asiático, que puede tener tallos de hasta 200 metros. Se importa a Europa desde antiguo. Es lo que se denomina actualmente médula, usada para cestería. Se cita una vez: "y un báculo o junco de las Indias, con su remate de plata" (La tía fingida: 1301).

Juncos: Scirpus holoschoenus. Planta muy frecuente en suelos frescos. Algunas citas son: "De la parte de esta enramada, si no me engaño, sale un tufo y olor harto más de torreznos asados que de juncos y tomillos" (II, 20: 698); "y hallaron entre unos verdes y crecidos juncos tendido otro peregrino" 
(Los trabajos de Persiles y Sigismunda IV, 2: 1331(II)). También citada como medicinal: "dame aquellos juncos, que me fatiga la piedra" (El viejo celoso: 1004(III)).

Juncos marinos: Juncus maritimus. Se conoce la siguiente cita: "así las rompiera como si fueran de juncos marinos o de hilachas de algodón" (II, 58: 990).

Lampazos: Arctium minus. De entre todas las especies vegetales europeas es la que tiene las hojas mayores. Sus frutos son los arrancamoños. Se conoce una cita de esta planta en el Quijote: "sino de algunas hojas verdes de lampazos y yedra entretejidas (I, 11: 98).

Lantejas: Lens culinaris. La única mención a esta legumbre es la de "lantejas los viernes" (I, 1:27).

Laurel, lauro, laureado: Laurus nobilis. Aparte de su importancia como planta simbólica, el aroma característico de las hojas de este árbol hace que se utilicen como condimento en guisos, encurtidos, adobo de aceitunas o conservas de pescado; o incluso para platos dulces. Una de las plantas más citadas (32 veces), en alusión directa, en la confección de coronas y en sentido figurado. Algunas de ellas son: "que yo prometo de ponerte una corona de laurel en la cabeza" (II, 55: 969); o "los cuales se coronaban con dos guirnaldas de verde laurel y de rojo amaranto tejidas" (II, 58: 990), cuando se aparecen las dos pastoras que habían decidido componer una nueva Arcadia. Era el "árbol a quien no ofende el rayo" (II, 16: 668).

Lentiscos: Pistacia lentiscus. La única mención que se hace de este árbolillo es: "Todo el bien suceda en colmo / entre desposados tales, / tan para en uno nascidos; / peras les ofrezca el olmo, / cerezas los carrascales, / guindas los mirtos floridos, / hallen perlas en los riscos, / uvas les den los lentiscos, / manzanas los algarrobos" (La Galatea III: 200(II)).

Limón: Citrus limon. El limonero fue introducido por los árabes probablemente en el siglo XI en la Península Ibérica. Algunas citas son: "hasta dos docenas de naranjas y limones" (Rinconete y Cortadillo: 587(II)); "El pintado camarón, con el partido limón y bien molida pimienta" (El rufián dichoso I: 367(III)).

Lino: Linum usitatissimum. Planta de uso más frecuente, que se cultivaba en los llamados linares. Con su fibra se tejían tejidos finos y bastos, que duraban muchos años. Se conocen dos citas: "estuviese ella rastrillando lino o trillando en las eras" (I, 25: 243); "y ésta es la hora en que ella está rastrillando una libra de lino" (II, 25: 747).

Lirio: Iris germanica. Esta especie es frecuentemente cultivada desde antiguo. Algunas citas son: ; "los cabellos, como lirios (II, 44: 886); "allí el cárdeno lirio" (La Galatea I: 66(II)); "y todos a una voz tus lirios de oro" (La casa de los celos y selvas de Ardenia III: 236(III)).

Madreselva: Lonicera periclymenum. Enredadera silvestre y cultivada de flores muy aromáticas. También se cultivan $L$. etrusca y $L$. implexa. Las dos citas que se conocen son: "traían guirnaldas de jazmines, rosas, 
amaranto y madreselva compuestas" (II, 20: 702); "y en medio venía un dispuesto pastor, coronado con una guirnalda de madreselva y de otras diferentes flores" (La Galatea II: 136(II).

Majagranzas: Rubia tinctorum. Se refiere a una planta tinctórea, la granza o rubia. Se cultivaba sembrándose de simiente; después de año y medio se arrancaba para sacar las raíces tuberosas, que se desecaban, y se majaban o se molían. El polvo resultante se utilizaba para teñir de rojizo. El compuesto causante del color es la alizarina. Se encuentra la expresión despectiva: "Sentaos, majagranzas" (II, 31: 791).

Malvas: Malva sylvestris. Planta herbácea nitrófila. Se ha encontrado una cita: "Eso allá se ha de entender -respondió Sancho- con los que nacieron en las malvas" (II, 4: 579).

Manzana, camuesas, manzano: Malus domestica. De las 10 menciones, varias de ellas son en sentido simbólico: "y verasme quedar más sano que una manzana" (I, 10: 92). En Los trabajos de Persiles y Sigismunda (II, 15: 1166(II)) se cita la raza de manzanas camuesas: "de otras pendían camuesas".

Manzanilla: Matricaria recutita. Planta herbácea medicinal. La única cita: "Cuelgue mi padre de su puerta el ramo, despoje de su jugo a Manzanilla" (El rufián dichoso I: 365(III)), que también podría referirse al tipo de vino sevillano.

Marañas: Quercus coccifera. Es el nombre que se da también a la coscoja, que da lugar a fitotopónimos con el de La Marañosa en Madrid. Las citas no se refieren a la planta.

Margaritas: Bellis perennis. Aunque el nombre de margarita es un genérico para varias especies de la familia de las compuestas, se utilizaba entonces según Gregorio de los Ríos sobre todo para esta especie. Se cita en dos ocasiones: "congratulándose con él de la margarita preciosa que había hallado en el desengaño de la bondad de su esposa" (I, 34: 365); "No es bien echar las margaritas a los puercos" (Coloquio de Cipión y Berganza: 995(II)).

Mastranzo: Mentha suaveolens. Esta planta aromática es citada una vez: "y ella derrama en coplas el poleo, con pa, y vereda, y el mastranzo, y juncia" (Viaje al Parnaso IV: 1284(III)).

Melón: Cucumis melo. Se menciona en sentido figurado: "que le abrieran de arriba abajo como una granada, o como a un melón muy maduro" (II, 32: 796).

Membrillo: Cydonia oblonga. El membrillo tiene connotaciones mágicas y se alaban los membrillos toledanos, aparte de utilizarse entonces ya el fruto para la elaboración del dulce llamado carne de membrillo. Son diez las referencias a esta planta; algunas de ellas son: "y unas tajadicas sutiles de carne de membrillo que le asienten el estómago y le ayuden a la digestión" (II, 47: 902); "Y así, aconsejada de una morisca, en un membrillo toledano dio a Tomás uno destos que llaman hechizos" (Licenciado Vidriera: 655(II)); "varilla de membrillo" (Coloquio de Cipión y Berganza: 935(II)). 
Mijo: Panicum miliaceum. Esta es la única cita que alude a esta especie: "sustentábame con pan de mijo" (Coloquio de Cipión y Berganza: 952(II)).

Mimbres: Salix fragilis. Las varetas de mimbre que se obtienen sobre todo de esta especie de sauce se utilizan para tejer: "y los tejados de mimbres, o por mejor decir, las paredes de mimbres" (Los trabajos de Persiles y Sigismunda II, 10: 1137(II)); o en cestería: "una cestilla / de blanca mimbre olorosa." (Pedro de Urdemalas III: 857(III)).

Mirra: Commiphora abyssinica. Árbol africano que suminsitra una resina aromática. Una mención es: "¿Y no nos vienen a dar / Mirra y su padre ocasión / de temer estos incestos?" (La entretenida I: 687 (III)), aunque en ella se refiere a nombre de persona. Otra es "la mirra no es de algún provecho" (La tía fingida: 1307).

Mirto: Myrtus communis. Este arbusto aromático también se llama arrayán o murta y vive silvestre en el este de España. También se cultiva profusamente. La única cita del Quijote es cuando: "atravesaron al jabalí poderoso sobre una acémila, y cubriéndole con matas de romero y con ramas de mirto, le llevaron, como en señal de victoriosos despojos, a unas grandes tiendas de campaña que en la mitad del bosque estaban puestas" (II, 34: 815). Hay otras en La Galatea y en Viaje al Parnaso.

Mostaza: Sinapis alba. La mostaza blanca corresponde a esta especie, aunque la negra es Brassica nigra. El grano de mostaza mencionado en la Biblia, que puede ser a lo que se refiera Cervantes es la especie arbórea de Asia occidental Salvadora persica, perteneciente a la familia Salvadoraceae. Lo cita cuando dice que "la tierra os pareció como un grano de mostaza" (II, 41: 863), y otras tres veces como referencia a pequeño tamaño.

Nabos: Brassica napus. Planta de huerta comestible y forrajera. Hay dos referencias en el Quijote: "que le ha tajado la cabeza cercén a cercén, como si fuera un nabo (I, 35: 366) o "el cual está acostumbrado a cabra, a vaca, a tocino, a cecina, a nabos y a cebollas" (II, 49: 918).

Naranjos, naranjas, azahar, naranjada: Citrus aurantium. Aunque probablemente hubiera ya árboles de frutos dulces, que habrían sido entonces introducidos desde Portugal, y corresponderían a la especie C. sinensis, los más abundantes serían los de fruto amargo, árboles ornamentales ya conocidos desde antiguo. Es citado en alusión directa en palabras de Maritornes: "y más cuando cuentan que se está la otra señora debajo de unos naranjos abrazada con su caballero" (I, 32: 321); en sentido figurado: "él es de hechura de una media naranja" (II, 8: 605); o como alimento: "hasta dos docenas de naranjas y limones" (Rinconete y Cortadillo: 587 (II)); o aromática: "olorosa más que la flor de azahar" (El rufián viudo, llamado Trampagos: 914 (III)).

Neguilla: Nigella gallica. Mala hierba de cultivo que se cita en tres ocasiones. Una de ellas es: "no entre en su viñas pulgón, / ni es su trigo la neguilla." (La Galatea III: 200 (II)). 
Nísperos, níspolas, mondaníspolas: Mespilus germanica. También se han nombrado a los frutos de algunos serbales, Sorbus con este nombre. El níspero japonés es especie introducida y cultivada como árbol frutal y se trata de Eriobotrya japonica, perteneciente también a la familia rosáceas. De las tres citas, dos de ellas son: "ahí nos tendemos en mitad de un prado y nos hartamos de bellotas y de nísperos" (II, 59: 999); "¿mondo yo, por dicha, níspolas?" (La entretenida: (III). El término mondaníspolas aparece en El rufián viudo, llamado Trampagos (905(III)).

Nuez, nogal: Juglans regia. Árbol cultivado que se utiliza como frutal, medicinal, maderero y para obtención de colorante. Se conocen 10 citas, algunas de las cuales son: "mostraba verter lágrimas del tamaño de nueces por los ojos" (II, 71: 1087); "al pie de un crescido nogal" (La Galatea V: $300(\mathrm{II}))$.

Oliva, olivo, olivar, aceitunas, aceite: Olea europaea. El olivar formaba parte del paisaje que conoció Cervantes, sobre todo en sus andanzas por Andalucía. Sin embargo solamente se menciana esta planta cuatro veces en el Quijote, bien el árbol o las aceitunas: "Esa oliva se haga luego rajas y se queme (I, 6: 64); "ni del famoso Betis las olivas" (1; 14: 120); "Hogaño no hay aceitunas, ni se halla una gota de vinagre en todo este pueblo" (II, 52: 952); "No faltaron aceitunas, aunque secas y sin adobo alguno, pero sabrosas y entretenidas" (II, 54: 961). Esta cita es de cuando el encuentro con los peregrinos y con Ricote, el morisco vecino de Sancho Panza, con los que comparten la comida. Las aceitunas secas y sin aliñar aún es posible encontrarlas en Aragón. En otra ocasión menciona "los molinos de aceite, los lagares del vino" (I, 28: 278). Naturalmente cita el aceite en muchas ocasiones. Una de ellas es: " $i$ Vengan alcancías, pez y resina en calderas de aceite ardiendo!” (II, 53: 955).

Olmo, álamo,: Ulmus minor. Álamo es nombre utilizado igualmente para Ulmus minor y para las especies del género Populus, árboles todos muy comunes en España. A Ulmus minor se le denomina olmo en general, pero en otras partes álamo negro, o simplemente álamo; también en ciertos lugares negrillo. Pero álamo negro también es nombre que se da a Populus nigra, aunque a las especies de Populus sea más frecuente denominarlas popularmente chopos. Como es bien sabido había la costumbre, sobre todo en Castilla, de plantar un olmo junto a la iglesia o en la plaza del pueblo, alrededor del cual se reunía el concejo y deliberaban los venerables del pueblo. Solía estar rodeado de un poyete de piedra para sentarse. En estos últimos años han muerto muchos de estos olmos centenarios, debido a una enfermedad que produce un hongo, y cuyas esporas transmite un insecto barrenador de la corteza de este árbol. Dicho insecto deja unas señales debajo de esta, parecidas a dibujos o gráficos. Por ello la tal enfermedad se llama grafiosis del olmo. Son árboles que viven en suelos frescos que son agostaderos en donde suelen medrar las praderas de grama, con frecuencia junto a cursos de agua, aunque sean estacionales. Son especies manejadas por el 
hombre desde tiempo inmemorial. Los olmos tienen una vida que de natural llega a unos 400 años, y después enferman en general de hongos que minan su leño, se ahuecan y se suelen morir, con frecuencia abatidos por un vendaval. Algunas citas de las 24 que se conocen son: "Sentábase en un poyo que debajo de un gran álamo está en nuestra plaza" (I, 51: 517); "Con esto se metieron en la alameda, y don Quijote se acomodó al pie de un olmo" (II, 28: 771); "dos días después que salieron de la alameda" (II, 29: 771); "porque venía de los Álamos de Medina del Campo" (II, 31: 789); "espetado en un asador de un olmo entero" (II, 20: 699); o dos veces más en (II, 54: 961). El dicho "pedir peras al olmo" se repite en tres ocasiones (I, 22: 209; II, 40: 852; II, 52: 947).

Orégano: Origanum vulgare. Planta perenne aromática, que es condimento muy importante por su utilización sobre todo en la matanza. Florece en pleno verano y es muy apreciada. En la actualidad se cultiva con frecuencia en huertos. Es citado en sentido figurado: "mas quiera Dios, tornó a decir, que orégano sea y no batanes" (I, 21: 188); "la otra es que se muestra en ella muy codicioso, y no querría que orégano fuese" (II, 36: 833).

Ortiga: Urtica dioica. Planta perenne urticante, aunque también es frecuente la especie anual $U$. urens. La cita es de La ilustre fregona (752 (II)): "áspera como una ortiga".

Ovas: Cladophora, Spyrogira. Se trata de especies de algas filamentosas que pertenecen a estos géneros. La cita es: "con cuerdas hechas de tejidas ovas" (Viaje al Parnaso V: 1299 (III))

Palmas, dátiles, datilados: Phoenix dactylifera. Es una de las especies más citadas, 48 veces, 19 de ellas en el Quijote, la mayoría en sentido simbólico, de galardón. Solamente en algunas ocasiones se menciona su fruta: "y no la comparéis a una palma que se mueve cargada de racimos de dátiles" (II, 21: 708). En dos ocasiones se refiere a borceguíes datilados (I; 37: 389; II; 18: 680), o sea del color del dátil.

Palmilla: Gladiolus communis. Es el nombre de esta planta, pero las citas se refieren al tejido típico de Cuenca.

Palmito: Chamaerops humilis. Se trata de la única palmera natural de la Península Ibérica, que vive en el sur y también en las islas Baleares. Se ha utilizado como fibra en cestería. Las dos citas son en alusión a todas las hojas que se encuentran rodeando al tronco y lo visten: "Enviad vos dinero -dijo Teresa-, que yo os lo vestiré como un palmito (II, 5: 587); "le traigo más vestido que un palmito" (El rufián viudo, llamado Trampagos: $904(\mathrm{III})$ ).

Pepinos: Cucumis sativus. La cita "sin que se les ofreciese ofrenda de pepinos ni de otra cosa arrojadiza" (Entremeses, Prólogo (III)) indica la costumbre de tirar pepinos en vez de tomates, cuando alguna obra de teatro no gustaba. Quizá de ello venga la expresión "un pepinazo". No se puede comparar en blandura; pero el tomate, de origen americano, aún no se 
había popularizado entonces. En otra ocasión cita en el Quijote al rey Pepino (I, 48: 495).

Pera, pero: Pyrus communis. Citada en 12 ocasiones, seis de ellas en el Quijote. Es frecuente el dicho "pedir peras al olmo" (I, 22: 209; II, 40: 852; II, 52: 947), en esta última ocasión cuando la dueña doña Rodríguez, del palacio de los duques, se queja de "la sinrazón y alevosía que un mal labrador tiene fecha a mi muy querida y amada hija" ante Don Quijote, para que este hiciera "que se casase con mi hija, en cumplimiento de la palabra que le dio de ser su esposo antes y primero que yogase con ella: porque pensar que el duque mi señor me ha de hacer justicia es pedir peras al olmo". En otras parece referirse a la disponibilidad que había de este fruto: "en quien vuestra merced pudiera escoger como entre peras" (I, 25: 243); "como entre peras podremos escoger sus nombres" (II, 67: 1062); o cuando Sancho una de las veces que se pone a soltar una larga ristra de refranes dice: "Y ahora se me ofrecen cuatro que venían aquí pintiparados, o como peras en tabaque, pero no los diré, porque al buen callar llaman Sancho." (II, 43: 875). El tabaque es un cestillo para fruta.

Pimienta: Piper nigrum. En dos ocasiones se alude a esta importantísima especia: "se comenzó a descargar la gran nave, que en ocho días no acabó de dar la mucha pimienta y otras riquísimas mercaderías que en su vientre encerradas tenía." (La española inglesa: 624(II)); "El pintado camarón, con el partido limón y bien molida pimienta" (El rufián dichoso I: 367(III)).

Pimientos: Capsicum annuum. Aunque de origen americano, ya estaba generalizado su uso en España en tiempos de Cervantes, según relato de Nicolas Monardes (1574), en el capítulo De la pimienta de las Indias: "la cual es conoscida en toda España, porque no ay jardín, ni huerta, ni macetón que no la tenga sembrada, por la hermosura del fruto que lleva. Unos pimientos son largos, otros redondos, otros de hechura de melones, otros de cerezas. Usan dellos en todos los guisados y potages, porque haze mejor gusto, que la pimienta común. Difieren en que las de la India cuestan muchos ducados: estotra no cuesta mas que sembrarla, porque en una planta ay especias para todo el año, con menos daño, y mas provecho nuestro." La cita es: "con su llamativo de alcaparrones ahogados en pimientos" (Rinconete y Cortadillo: 587(II)).

Pino: Pinus halepensis. El llamado pino carrasco es el más frecuente en las zonas áridas de la mitad sur de España. Algunas citas son: "que era un mancebo como un pino de oro" (II, 50: 933); "el caballo arrendado a un pino" (La Galatea V: 299(II)).

Piñones: Pinus pinea. Son la semilla del pino aparasolado o piñonero, que gusta de vivir en sustratos arenosos. Es muy frecuente en la costa suroeste de España, aunque se cultiva en el interior. El piñón es un fruto seco muy apreciado para la elaboración de dulces y como aderezo de ciertos platos típicos. La única referencia, en lo que probablemente se refiere a 
los dientes, es: “¿Mal año para piñones mondados, que más blancos ni más lindos sean!" (El celoso extremeño: 729(II)).

Piruétanos, peruétano: Pyrus bourgaeana. Peral silvestre que cría perillas muy duras que se pueden comer en caso de necesidad extrema. El escudero del caballero del Bosque dice "que yo no tengo hecho el estómago a tagarninas, ni a piruétanos, ni a raíces de los montes (II, 13: 243); o "sana como un peruétano" (El rufián viudo, llamado Trampagos: 901(III)).

Plátano: Platanus orientalis. Árbol ornamental que se planta frecuentemente en paseos y avenidas. Es oriundo de la región mediterránea oriental. Se cita en Los trabajos de Persiles y Sigismunda (III, 5: 1230(II)) (ver cinamomo) y (II, 3: 1101(II)): "como no des en el disparate de amar a un toro, ni en el que dio el que adoró el plátano", refiriéndose al rey Jerjes.

Poleo: Mentha pulegium. Hierba aromática que vive en zonas encharcadas y florece en pleno verano. Se conoce una cita del Viaje al Parnaso (IV: 1283(III)): y ella derrama en coplas el poleo".

Quejigo: Quercus faginea. Este árbol de hoja caduca se denomina roble en muchos lugares de España. Es citado una vez: "Cuatro se arracimaron a un quejigo" (Viaje al Parnaso VII: 1330(III)).

Rábanos: Raphanus sativus. Esta planta de huerta se cita en dos ocasiones, una de ellas como "un grande haz de rábanos" (Rinconete y Cortadillo: 587(II)).

Resina, brea, pez, teoso pino: Pinus pinaster. El pino resinero es de gran utilidad por su resina y los productos derivados que de ella se obtienen. Algunas de las 10 citas son: " Vengan alcancías, pez y resina en calderas de aceite ardiendo!" (II, 53: 955); "a la luz de una raja de teoso pino" (La Galatea VI: 408(II)); "No me hüela el soldado otros olores / que al olor de la pez y de resina" (El cerco de Numancia I: 1124(III)).

Retama: Retama sphaerocarpa. Es la retama más común en la Península Ibérica, aunque así se llaman también a otros matorrales inermes, sin pinchos, como Spartium junceum (retama de olor) o Cytisus scoparius (retama de escobas). La utiliza Sancho para marcar el camino al salir de Sierra Morena (I, 25: 274).

Roble: Quercus robur. Árboles corpulentos. De las tres citas, en una de ellas se alude a su fortaleza: "roble que nunca inclina / la altiva rama al cierzo que le toca" (La Galatea III: 176(II)).

Romana: Tanacetum balsamita. Nombre de esta planta, aunque en el dicho (II, 49) se refiera al artilugio que se utiliza para pesar.

Romero: Rosmarinus officinalis. Importante planta medicinal, que como indica su nombre científico específico, era propia de oficina de botica. También eran bien conocidas sus propiedades por la gente de campo. De esta manera curó el cabrero la tremenda herida que tenía don $Q u i-$ jote en la oreja: "Y tomando algunas hojas de romero, de mucho que por allí había, las mascó y las mezcló con un poco de sal" (I, 11: 102). Forma parte del famoso bálsamo de Fierabras (I, 10: 92), cuya fórmula es: "aceite, vino, sal y romero para hacer el salutífero bálsamo" (I, 
17: 148). Además de la historia de Fierabrás, es probable que Cervantes conociera el bálsamo de Fioravanti, de moda en el siglo XVI y famoso en toda Europa en aquella época, y al que se atribuían efectos milagrosos. Era tomado como panacea para la curación de cualquier dolencia, aunque se utilizara sobre todo para sanar heridas y por vía externa.

Rosa, rosadas, rosal: Rosa. Género botánico difícil desde el punto de vista sistemático. Hay una gran variación de rosas silvestres y cultivadas. Una de las plantas más mencionadas ( 27 veces) y además en muchas de las obras, en alusión directa, por su uso ornamental y en sentido figurado en múltiples dichos o para indicar color. Algunas citas son: "porque yo sé bien a lo que huele aquella rosa entre espinas" (I, 31: 312); "Cortada la rosa del rosal, ¡con qué brevedad y facilidad se marchita!" (La gitanilla: 463(II)); " ¡Oh rosa puesta entre espinas / para gloria de las rosas!” ( $L a$ gran sultana Doña Catalina de Oviedo III: 560(III)); "y el rosal, que alegra el alma," (Pedro de Urdemalas I: 808(III)).

Rubión: Fagopyrum esculentum. Aunque se considera como variedad de trigo, en La Mancha se llama así al alforfón, que es un pseudocereal. Se menciona en tres ocasiones en el Quijote; dos de ellas son las siguientes: "No era sino rubión" (I, 31: 310); o " y por más señas dice que era rubión" (II, 32: 801).

Ruibarbo: Rheum palmatum. Hierba perenne utilizada como purgante. La cita en sentido figurado alude a esa virtud: "tienen necesidad de un poco de ruibarbo para purgar la demasiada cólera suya" (I, 6: 65).

Sabina: Juniperus phoenicea. Árbol de madera muy durable usada en construcción tradicional. Solamente aparece una cita: "en gruesos troncos de sabina sustentado" (Los trabajos de Persiles y Sigismunda II, 10: 1136(II)).

Sauce, sauceda: Salix alba. Dentro de este complejo género botánico, este es el sauce arbóreo más frecuente, que vive siempre junto en los cauces de las corrientes de agua. Es citado en 13 ocasiones, como lugar fresco y de sombra. Una de ellas es: "las atase muy bien juntas al tronco de un álamo o sauce que allí estaba" (II, 29: 772).

Tabaco: Nicotiana tabacum. La única cita es del Viaje al Parnaso (VIII: 1337 (III)): "Esto que se recoge es el tabaco / que a los vaguidos sirve de cabeza".

Tagarninas: Scolymus hispanicus. El cardillo o tagarnina es una verdura silvestre muy apreciada aún hoy día. Aunque el escudero del bosque no tenía "hecho el estómago a tagarninas, ni a piruétanos, ni a raíces de los montes (II, 13: 243).

Taray: Tamarix gallica. Árbol que vive sobre suelos salobres. Es la especie más frecuente en España, aunque también viven otras, como T. parviflo$r a$, que se cultiva como ornamental. Según se menciona en El rufián viudo, llamado Trampagos (901(III)): "y que con agua de taray pudiera vivir, si la bebiera, setenta años", debía ser este remedio muy saludable para alargar la edad, ya que en aquellos tiempos era excepcional alcanzar esos años. 
Tártagos: Euphorbia lathyris. Hay una cita que se refiere a la pena de Sancho al ver sufrir a su burro, lo mismo que si tomara esta planta, que como se sabe tiene efectos de purga drástica y debe producir retortijones y serio malestar: "puesto que cada vez que veía levantar las vejigas en el aire y caer sobre las ancas de su rucio eran para el tártagos y sustos de muerte" (II, 11: 628).

Tejo: Taxus baccata. Árbol relativamente frecuente que aparece disperso y aislado en toda España, debido a su dispersión ornitócora o por pájaros, pero que a veces forman tejedas o tejeras, lo que han dado lugar a fitotopónimos como el de Sierra Tejeda en Málaga, o el de Tejera Negra en Guadalajara. Se cita una vez en el Quijote: "coronados con guirnaldas, que, a lo que después pareció, eran cuál de tejo y cuál de ciprés" (I, 13: 116).

Terebinto: Pistacia terebinthus. Este arbolillo o arbusto llamado cornicabra o incienso, porque se usa como tal, es mencionado una vez: "en el valle de Terebinto, según se cuenta en el libro de los Reyes" (I, Prólogo: 11).

Tomillos: Thymus zygis. Es el más común en España, tan rica en tomillos; quizá por eso esta especie es la que se considera más genuina de nuestro país. Aunque también pudiera referirse a $T$. vulgaris, que vive en la mitad este de España, y que se cultiva con frecuencia y desde tiempo de los Romanos. "De la parte de esta enramada, si no me engaño, sale un tufo y olor harto más de torreznos asados que de juncos y tomillos" (II, 20: 698).

Trigo, candeal, trechel, panes, trastrigo: Triticum aestivum. Otra de las plantas más citadas ( 29 veces), aludiendo a su cultivo, a su uso como comestible, o en sentido figurado, entre otras cosas refiriéndose al tamaño del grano de trigo; o en varias ocasiones en el dicho "buscar pan de trastrigo" (I; 7: 72; I, 67: 1062). En II, 27: 763 le denomina pan: "porque no tenía para qué retar a los muertos, a las aguas, ni a los panes".

Tueras, tueros: Citrullus colocynthis. En dos ocasiones se refiere al amargor de esta pequeña sandía silvestre, de efectos purgantes: "y tan amargo, que en su comparación son dulces las tueras" (II, 39: 846); "no hallen en el verde prado para sustentarse sino amargos tueros" (La Galatea I: 37(II)).

Verbena: Verbena officinalis. Esta planta herbácea tiene connotaciones más bien mágicas dentro de sus propiedades curativas. Se menciona una vez: "Aquí verás la verbena, / de raras virtudes llena," (Pedro de Urdemalas I: 808(III)).

Vid, cepas, majuelo, viña, parra, veduño, uvas, pasas, albilla, mozcatel, vino, vinagre, aguardiente: Vitis vinifera. Esta planta se menciona en 37 ocasiones, lo que prueba su importancia en nuestra cultura, con frecuencia el vino como recurso alimenticio energético, o como fuente de otros productos, además de todas sus connotaciones festivas. De tipos de vinos de entonces habla en varias ocasiones en el Quijote y sobre todo en el Licenciado Vidriera: "Madrigal, Coca, Alaejos, y a la Imperial más que Ciudad Real, recámara del Dios de la risa; ofreció a Esquivias, a Alanís, 
a Cazalla, Guadalcanal y la Membrilla, sin que se olvidase de Rivadavia y de Descargamaría. Finalmente más vinos nombró el huesped, y más les dio, que pudo tener en sus bodegas el mismo Baco".

Yezgos: Sambucus ebulus. Planta perenne herbácea maloliente. Alude en una ocasión a este planta, en donde parece referirse a virtudes medicinales: "porque ha de ser distilada / de ciertas yerbas y yezgos" (La gran sultana doña Catalina de Oviedo II: 500(III)).

Zahareña: Sideritis hirsuta. Aunque nombre de planta, todas las veces alude a su otro sentido de áspero, sobre todo refiriéndose a mujeres: "zahareña como villana de Sayago" (La ilustre fregona: 752(II)).

Zanahorias: Daucus carota. Citada una vez en sentido figurado: "como yo esté harto, eso me hace que sea de zanahorias que de perdices" (II, 55: 974).

Zarzas: Rubus ulmifolius. Las zarzas es un genérico con el que se denominan sobre todo a especies del género Rubus; la más frecuente de ellas la especie considerada, que forma por todos lados zarzales y espinales acompañada a veces de otros matorrales espinosos, en cuanto hay cierta humedad en los suelos. En verano y otoño se recolectan sus frutos, las zarzamoras, que se toman crudas o con las que se pueden elaborar mermeladas. Aunque se trata de especies silvestres, han sido manejadas y utilizadas para lindes y cerramientos de viñas, como indica la cita de La Galatea (VI: 334(II)): "como suelen estar en los vallados de las guardadas viñas las espinosas zarzas".

*Zumaque: Rhus coriaria. Se trata de una especie introducida en España y que vive en la actualidad asilvestrada. Es usada para curtir y teñir de negro. Una única vez se menciona esta planta: "no vale nada el zumaque y vidrio molido" (La tía fingida: 1307)

Otros muchos nombres citados lo son de plantas o tienen relación con el mundo vegetal, como por ejemplo: Amarilis, Arce, Artemisa, Flora, Ginebra, Jacintos, Narciso, Pimpinela, Corchuelo, Nogales. A continuación también se citan algunos referentes a partes y formaciones, aunque sea en sentido figurado: "raíces tiene tan hondas echadas" (II, 43), "que como raíz escondida, que con el tiempo venga después a brotar, y echar frutos venenosos en España" (II, 65), "quitarme allá esas pajas" (I, 7), "que así a humo de pajas hago esto" (I, 10), "enderazando las tiernas varas de su juventud" (El casamiento engañoso), "árbol en cuyo tronco no se hubiese sentado a cantar" (El casamiento engañoso), "mándole yo a los leños movibles" (II, 37), "los árboles destas montañas son mi compañía" (I, 14), "que la escribiésemos, como hacían los antiguos, en hojas de árboles" (I, 25), "flor de la fermosura" (I, 8), "los demás días se los pasaban en flores" (I, 10), "arma de las flores de oro" (I, 17), "la flor de la honestidad" (I, 33), "flor de la caballería andante" (I, 46), "no la ha cortado el estambre de la vida" (II, 38), "de fruta seca" (I, 10), "coger el fruto de nuestros trabajos" (I, 46), "que todo sería de poco fruto" (II, 17), "quitar de sobre la faz de la tierra tan mala simiente" (I, 8); o sus referencias a bosques, selvas, florestas arboleda, prados, jardín, güerta del rey, prados, pradecillos y yerba. 


\section{RECAPITULACIÓN}

Se han recogido 821 citas, 366 de ellas en el Quijote, en que aparecen 219 nombres diferentes de plantas o alusiones a ellas o a productos vegetales. En total se hace referencia a 150 especies vegetales, 100 de ellas en el Quijote. Además se añaden siete términos de nombres de plantas que se citan en otro sentido.

$\mathrm{Si}$ se comparan estos resultados con otros trabajos realizados de manera similar sobre las plantas de la Biblia, en que resultan 128 especies citadas (Moldenke \& Moldenke, 2002) o el de las obras completas (en total 43) de Shakespeare (Ellacombe, 1884), en las que se mencionan 147 especies vegetales, se concluye que son números resultantes muy parecidos. Además se encuentran 81 especies que son comunes en las obras de Shakespeare y de Cervantes.

Las especies más citadas son el trigo, la vid y el olivo, más sus productos derivados, que son básicos en la cultura mediterránea; la encina y el alcornoque, árboles de gran importancia y comunes en los ecosistemas de la Península Ibérica; la palmera, el laurel, el ciprés y el peral; y la rosa y la hiedra. De estos, siete de ellos son plantas arbóreas. Todas ellas son especies vegetales cultivadas, salvo la encina y el alcornoque, que son silvestres y manejadas desde antiguo. La hiedra, el rosal y el laurel son plantas tanto silvestres como cultivadas.

Haciendo un pequeño análisis numérico se observa que se mencionan en alusión directa: 44; árboles 28; otras plantas 14; formaciones vegetales 5. Por su uso: 81 ; comestible 32 ; ornamental 9 ; medicinal 8 ; aromática 7 , utensilios 12; bastón 5; guirnalda o corona 8; vestimenta 4 . Y en sentido figurado: 101 ; lenguaje poético 35 ; dichos 52 ; color 7 ; tamaño 5 ; sabor 3; olor 3; nombre propio 8 , etimología 2 . Las alusiones directas indican conocimiento de las especies más importantes, que formaban parte de la vida cotidiana. Las citas en sentido figurado son de gran interés, porque expresan inconscientemente, al formar parte del lenguaje, que eran plantas de cierta importancia en aquella época, independiente del conocimiento directo. Al ser de uso normal en el lenguaje, sin duda eran conocidas y probablemente eran de uso o manejo habitual.

\section{REFERENCIAS BIBLIOGRÁFICAS}

Camacho Morfín, L. \& D. Camacho Morfín (2001). "Los usos del romero (Rosmarinus officinalis) vistos por un escritor del siglo de Oro español”, Delpinoa 43: 109.

Carabaza, J., E. García Sánchez, J. Hernández Bermejo \& A. Jiménez Ramírez (2004). Árboles y arbustos de Al-Andalus. Estudios Árabes e Islámicos: Monografías. 8. CSIC. Madrid. 349 págs.

Ceballos, L. (1965). Flora del "Quijote". Discurso del Excmo. Sr. D. Luis Ceballos Fernández de Córdoba de entrada en la Real Academia de la Lengua Española. Madrid. 41 págs.

Ceballos, L. (1996). La Flora del Quijote. Ed. Soluciones Plenas / Grupo S.L.

Cervantes, M. (1940). Obras completas. M. Aguilar Editor. Madrid. 1956 págs. 
Cervantes, M. (1994). Obra completa II. Galatea. Novelas ejemplares. Persiles. Edición de Florencio Sevilla \& Antonio Rey. Centro de Estudios Cervantinos. Alcalá de Henares. 1384 págs.

Cervantes, M. (1995). Obra completa III. Comedias. Entremeses. Viaje al Parnaso. Poesías. Edición de Florencio Sevilla \& Antonio Rey. Centro de Estudios Cervantinos. Alcalá de Henares. 1421 págs.

Cervantes, M. (2004). Don Quijote de la Mancha. Edición de Francisco Rico. IV Centenario. Real Academia Española. Asociación de Academias de la Lengua Española. Madrid. 1253+CI págs,

Colmeiro, M. (1895). Noticia sucinta de los animales y plantas que mencionó Cervantes en El Quijote, con nociones históricas acerca del tabaco, chocolate, café y té, cuyo uso no conoció el ingenioso hidalgo. Madrid. 15 págs.

Ellacombe, H. N. (1884). The Plant-lore and Garden-craft of Shakespeare. W. Satchell and Co., London. Second edition. 438 págs.

García Río, R., M. I. Hernández Pérez, J. Charco \& M. P. García Río (2002). Guía didáctica de los árboles y arbustos de la comarca de Puertollano. Ayuntamiento de Puertollano. 144 págs.

Gómez FernÁNDEZ, J. R. (2005). "La Etnobotánica de El Quijote”, Quercus 233. Cuadernillo especial dedicado a Castilla-La Mancha: 7-9.

GómEZ TEJEDOR, J. (1994). Un naturalista ante "El Quijote". Ediciones Mensajero. Bilbao. 189 págs.

LÓPEZ GARCía, M. L. (2005). Diálogo de encinas en El Quijote. ARBA (Asociación para la repoblación del bosque autóctono). Madrid. 28 págs.

Moldenke, H. N. \& A. L. Moldenke (2002). Plants of the Bible. Kegan Paul. London. 384 págs.

MONARDES, N. (1574). La historia medicinal de las cosas que se traen de nuestras Indias Occidentales. Edición facsimil de J. M. López Piñero (1989). Ministerio de Sanidad y Consumo. Madrid. 291 págs.

Moreno, M. (2005) "De lo que hubiere en el libro de El ingenioso hidalgo don Quijote de la Mancha en relación con la botánica”, Bol. Real Soc. Española Hist. Nat. (Actas) 102: 26 págs. [en prensa].

Prieto, J. M. (2005). "Literatura y farmacología. El bálsamo de Fierabrás”, Boletín Latinoamericano y del Caribe de plantas medicinales y aromáticas (BLACPMA) [revista en soporte electrónico] 4(3): 48-51.

Ríos, Gregorio de los (1620). Agricultura de jardines. Edición facsimil de J. Fernández Pérez \& I. González Tascón (eds.) (1991), extractado de la obra Agricultura General de Alonso de Herrera. Real Jardín Botánico de Madrid. 352 págs.

Valle Nieto, A. del (2002). "Botica y farmacia en el Quijote", Anales Real Acad. Nac. Farm. 68 (4): 693-734.

\begin{abstract}
Resumen
Se presenta todos los datos referentes al mundo vegetal obtenidos en la lectura de las obras completas de Cervantes. Estos se ordenan alfabéticamente según los nombres que aparecen en dichas obras. Se da el nombre científico equivalente de cada planta a la que se alude, se incluyen una o más referencias con la expresión en la que aparece, detallando la obra, capítulo y página. Además se comentan aspectos botánicos e históricos de las diferentes especies.
\end{abstract}

Palabras clave: Cervantes, Quijote, obras completas, especies vegetales. 


\begin{abstract}
Reviewing the complete works of Cervantes and noting all mentions of plants species, all the names that appear are ordered alphabetically and their scientific names are given. One o more references are cited. Comments about botanical and historical aspects are included.
\end{abstract}

Key words: Cervantes, Quixote, complete works, plants species. 